\title{
INVESTIGATING THE EFFECT OF DISTANCE AND DIAMETER RATIO OF ELLIPTICAL PILES ON THE AMOUNT OF FORCE EXERTED BY WAVES IN THE PILE GROUPS WITH REGULAR LAYOUT
}

\author{
M. Ghatarband ${ }^{a}$, M. Behdarvandi Askar ${ }^{\text {** }}$ \\ a Department of Offshore Structures, Faculty of Marine Engineering, Khorramshahr University of Marine Science and Technology, \\ Iran, e-mails: Ghatarband@yahoo.com, *sazehenteghal@yahoo.com
}

Received: 18.12.2017 / Accepted: 30.01.2018 / Revised: 08.04.2018 / Available online: 31.05.2018

DOI: 10.2478/jaes-2018-0005

KEYWORDS: Wave forces, Pile Groups, Elliptical Piles, Numerical Modeling.

\begin{abstract}
:
Today, advanced countries compete enormously for further exploitation in the offshore area, for its enormous fresh resources and space. Therefore, these competitions will double the importance of these types of structures. As it is known, the most important part in the design of the offshore structures is the design of the piles on which the structure will be placed. Engineers have always been trying to build these types of structures with the least cost and the highest safety factor. In this research, the effect of distance and the ratio of the elliptical pile diameters on the strength of the pile group was evaluated using numerical modeling. Five different states of diameter ratios including: 1.2, 1.4, 2, 2.5, 3 and five different distance ratios were investigated. The results demonstrate that with the increase in the diameter ratio, the amount of force decreases while it increases as the distance ratio rises.
\end{abstract}

\section{INTRODUCTION}

Deng and Yang (2014), applied high frequency analysis on waves in vertical cylinders and concluded that interactions of nonlinear waves with structures causes the formation of wave run up in high frequencies (Deng and Yang, 2014). Wang et al. (2012), experimentally studied and monitored the interaction between waves and vertical cylinder wave run-ups and concluded various results (Wang et al, 2012). Isaacson's Theory (1978) proposed a theoretical Conidial wave approach with run up estimation on a large circular cylinder in the shallow water, and showed that, although the Conidial theory is less complete than wave run up theory, it is better and more complete than the linear propagation theory (Theory ,1978).

Studies by Galvin and Hallermeir (1972), Hallermeir (1976), and Haney and Berbich (1982) investigated the wave height distribution around the thin piles, in which the propagation parameters were small and the flow effects were usually dominant (Hallermeir; 1976). Galvin and Hallermeir (1972), studied the run up wave phenomenon on huge amount of sections and stated that the run up wave distribution on circular cylinder has been symmetric (Galvin and Hallermeir, 1972). Haney and Herbich (1982) studied the run up wave phenomenon around the vertical and steep piles. In this study, run up wave data were presented as a function of the maximum estimated velocity from crest wave velocity under a nonlinear regular form. From the hydraulic point of view, the run up wave interpretation in these papers is more tangible in terms of height and velocity parameters. Although, the results for a very limited range of non-dimensional parameters were outside the scattering regime, it is surprising that the scattering is very small in the observation results (Haney and Herbich, 1982).

\section{MATERIALS AND METHODS}

As shown in figure 1, the pile group arrangements are such that nine elliptical piles with five different diameter ratios as well as five different to distance to diameter ratios are placed against the waves. For more convenient analysis, the results of the elliptical piles are divided into three rows namely A, B, and C. Each column is also numbered 1,2 , and 3 . Note that in this research, the ratio of the diameters $\mathrm{Z}=(\mathrm{L} / \mathrm{B})$ is the ratio of longest (major) to shortest (minor) ellipse diameter. This study uses ratios of 1.2, 1.4, 2, 2.5, and 3. It is obvious that, when the diameter ratio is 1.2 , the ellipsoid geometry is closer to the circle, and in the diameter ratio of 3 the ellipsoid becomes more elongated and smaller in thickness. Also, the distance to the average diameter ratio can be explained as follows:

$$
\mathrm{S} / \mathrm{D}=\frac{\mathrm{S}}{\frac{\mathrm{L}+\mathrm{B}}{2}}
$$

where, $\mathrm{L}$ is the longest diameter of the ellipse, $\mathrm{B}$ is the shortest diameter, $\mathrm{S}$ is the distance between the ellipses and, $\mathrm{D}$ is the mean ellipse diameter. In this modeling, the Flow-3D software was employed and firstly, the model geometries were drawn at AutoCAD 3D and then transferred to Flow-3D model. 


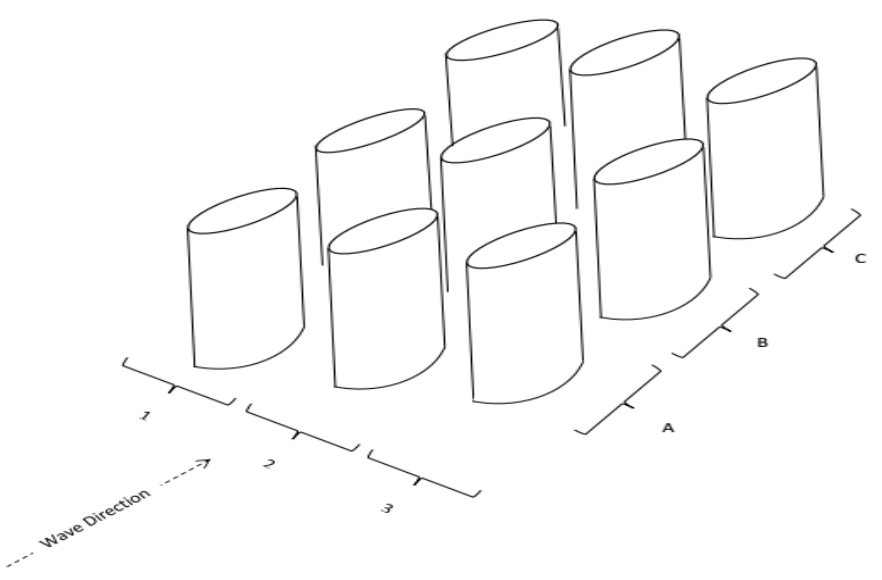

Figure 1.Types of layout and elliptical group pile naming
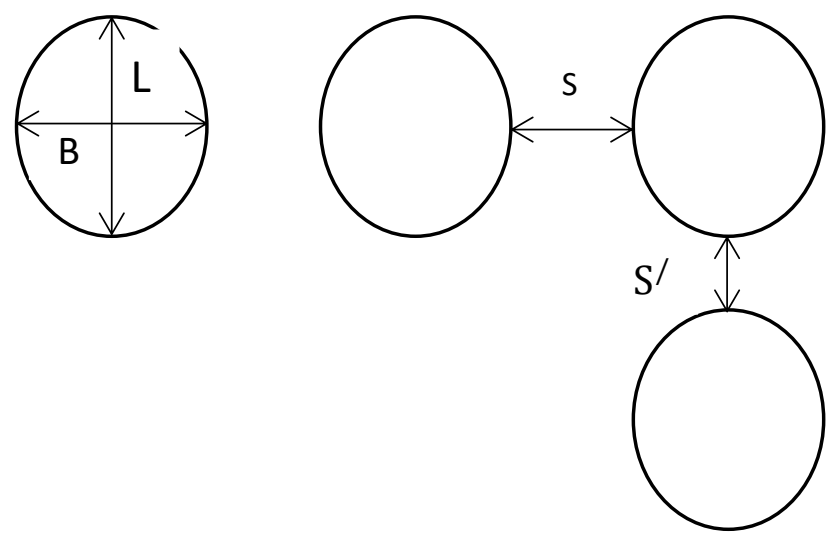

Figure 2. Schematic representation of the longitudinal and transverse distance of the elliptical piles

Table 1. Various scenarios being evaluated in this research

\begin{tabular}{|c|c|c|}
\hline Type of Piles Geometry & Diameter Ratios Z=(L/B) & $\begin{array}{c}\text { The distance to mean ellipse diameter in equal } \\
\text { longitudinal and transverse distances in regular } \\
\text { layout }(\mathrm{S} / \mathrm{D})\end{array}$ \\
\hline Ellipsoid & 5 States & 5 States \\
\hline
\end{tabular}

Table 2. Calibration model using mesh size

\begin{tabular}{|c|c|c|c|}
\hline Mesh & $\begin{array}{c}\text { Element Number in X and Y } \\
\text { Direction }\end{array}$ & Mesh Size & $\begin{array}{c}\text { Mean Absolute Percentage } \\
\text { Error (MAPE) }\end{array}$ \\
\hline Number 1 & $1715 \times 1000$ & 1.4 & $29.82 \%$ \\
\hline Number 2 & $2651 \times 1505$ & 1 & $15.23 \%$ \\
\hline Number 3 & $3235 \times 2800$ & 0.47 & $5.68 \%$ \\
\hline
\end{tabular}

The numerical model sensitivity to meshing has always been one of the important issues in numerical studies (Rashidinasab, BehdarvandiAskar, 2017).

In order to calibrate the model according to the mesh size, three different mesh sizes were evaluated. The final mesh size of 0.47 $m$ was chosen based on the error obtained from each mesh size. As it is known, the acceptance error in the numerical modeling is below 7\% (Bahadori, BehdarvandiAskar, 2016). Therefore, meshing number three was employed as an acceptable one for this modeling.
Fkiw-3D is a computer program with many general applications and capabilities. The user can simulate different models in a wide range of flow phenomena by importing information. In this section, the fluid motion equations used in the software will be noticed. The software uses differential approximation and finite volume for temporal and spatial calculations of variables in motion equations. The differential equations to be solved are written in Cartesian coordinates $(\mathrm{x}, \mathrm{y}$, and $\mathrm{z}$ ). The mass continuity equation is generally is stated as follows (Ebrahimi, et.al, 2015) 
Momentum equations (Navier-Stokes Equations) for fluid velocity components in three coordinate directions $\mathrm{x}, \mathrm{y}$, and $\mathrm{z}$ can be expressed by a series of additional terms as follows (Deilami-Tarifietal, 2016).

$$
\begin{gathered}
V_{\mathrm{F}} \frac{\partial \rho}{\partial \mathrm{t}}+\frac{\partial}{\partial \mathrm{x}}\left(\rho u A_{y}\right)+\mathrm{R} \frac{\partial}{\partial \mathrm{y}}\left(\rho_{v} A_{y}\right)+\frac{\partial}{\partial \mathrm{z}}\left(p w A_{z}\right)+\varepsilon \frac{p u A_{X}}{x}=R_{D I F}+R_{S O R} \\
\frac{\partial \mathrm{u}}{\partial \mathrm{t}}+\frac{1}{V_{F}}\left\{u A_{3} \frac{\partial \mathrm{u}}{\partial \mathrm{x}}+v R A \frac{\partial u}{\partial y}+w A_{2} \frac{\partial u}{\partial z}\right\}-\varepsilon \frac{A_{y} y^{2}}{X V_{y}}=\frac{1}{\rho} \frac{\partial p}{\rho \partial x}+G_{x}-f_{x}-b_{x}-\frac{R_{S O R}}{\rho V_{x}}\left(u-u_{w}-\delta u_{s}\right) \\
\frac{\partial \mathrm{v}}{\partial \mathrm{t}}-\frac{1}{\mathrm{~V}_{\mathrm{F}}}\left\{\mathrm{uA}_{3} \frac{\partial \mathrm{v}}{\partial \mathrm{x}}+\mathrm{vRA}_{\mathrm{y}} \frac{\partial \mathrm{v}}{\partial \mathrm{y}}+\mathrm{wA}_{\mathrm{z}} \frac{\partial \mathrm{v}}{\partial \mathrm{z}}\right\}+\varepsilon \frac{\mathrm{Auv}}{\mathrm{XV}}=-\frac{1}{\rho}\left(\mathrm{R} \frac{\partial \mathrm{p}}{\partial \mathrm{y}}\right)+\mathrm{G}_{\mathrm{y}}-\mathrm{f}_{\mathrm{y}}-\mathrm{b}_{\mathrm{y}}-\frac{\mathrm{R}_{\mathrm{SOR}}}{\rho V_{\mathrm{F}}}\left(\mathrm{V}-\mathrm{V}_{\mathrm{w}}-\delta \mathrm{v}_{\mathrm{s}}\right) \\
\frac{\partial w}{\partial t}+\frac{1}{V_{F}}\left\{u A_{3} \frac{\partial \mathrm{w}}{\partial \mathrm{x}}+v R A_{y} \frac{\partial w}{\partial y}+w A_{Z} \frac{\partial w}{\partial z}\right\}=-\frac{1}{\rho} \frac{\partial p}{\partial Z}+G_{Z}-f_{Z}-b_{Z}-\frac{R_{S O R}}{\rho V_{F}}\left(W-W_{w}-\delta W_{S}\right)
\end{gathered}
$$

The stock's wave of order five was chosen with wavelength of $33 \mathrm{~m}$ a height of $4.7 \mathrm{~m}$.
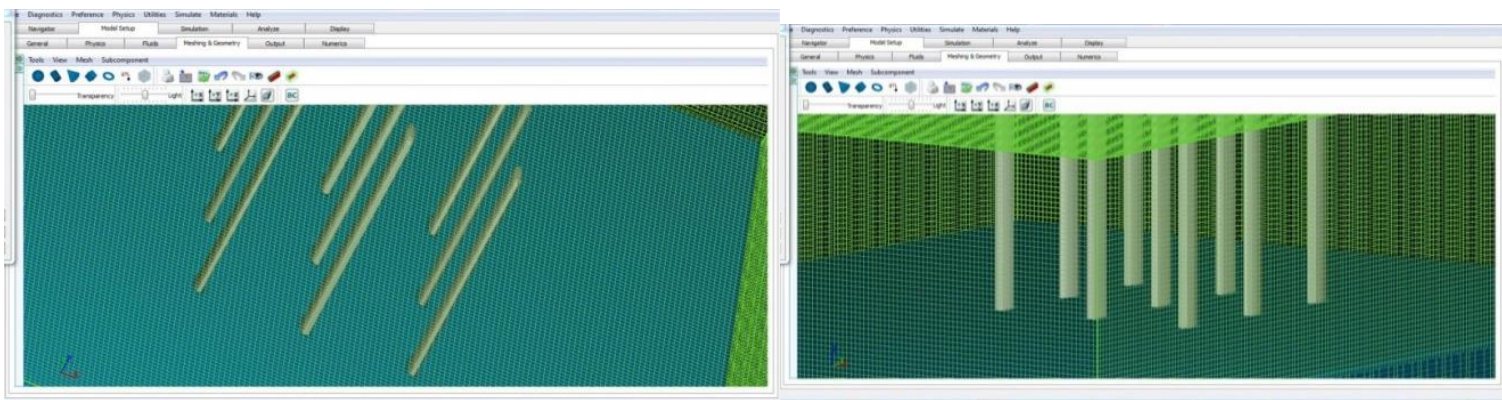

Figure 3.An illustration of group piles meshing in numerical modeling

\section{DISCUSSION AND CONCLUSION}

As it inferred from figure 4 to 18 , in the elliptical pile groups, the inserted force to each individual pile depends on their thickness and spacing, so that with increasing Z, which is the ratio of the longest diameter to the smallest one in the ellipse, the amount of inserted force from the wave to the piles will be reduced. That is, the highest amount of exerted forces are related to the diameter ratio of $Z=1.2$ and the lowest forces are related to the diameter ratio of $Z=3$.

The reason for this phenomenon is that with increasing $\mathrm{Z}$, the large ellipse diameter which is parallel to the wave is increased, which means that pile thickness decreases in the direction of the wave propagation. Having the pile thickness reduced against the wave propagation, the surface impacted by the force decreases and consequently the amount of force applied to the pile decreases. Also, in each row, for example, in rows A, B and C, the maximum force is applied to the middle piles or pile number two relative to the other piles in common row. The reason explaining this phenomenon is that as the passage channel for the pile 2 in each row becomes narrower due to the effect of piles 1 and 3, the wave velocity passing from pile 2 increases, and therefore, with increasing the velocity, the inserted force into the pile 2 increases. This phenomenon is more pronounced on pile $\mathrm{A} 2$ rather than piles $\mathrm{B} 2$ and $\mathrm{C} 2$, as the wave reaches the piles in row $\mathrm{B}$ and $\mathrm{C}$, it loses some of its energy. Also, by increasing the distance between the piles, the force applied to the piles decreases so that the most forces are related to $(\mathrm{S} / \mathrm{D})=$ 1.8 and the lowest forces are related to $(\mathrm{S} / \mathrm{D})=9$. Perhaps the reason to explain this phenomenon is that, with a small amount of distance between the piles, the wave run up and consequently, the piles contact area with wave's increases, which boosts the amount of force applied to the piles. These results are generally evident in all figures 4 to 18 . Figures 19 to 21 also indicate that the amount of applied force to the piles that are closer to the location of the wave propagation to the structure is more than those piles with the same direction, so that it can be stated that in terms the magnitude of applied force A1> B1> C1. It should be noted that other charts are not reported for avoiding repetitions.

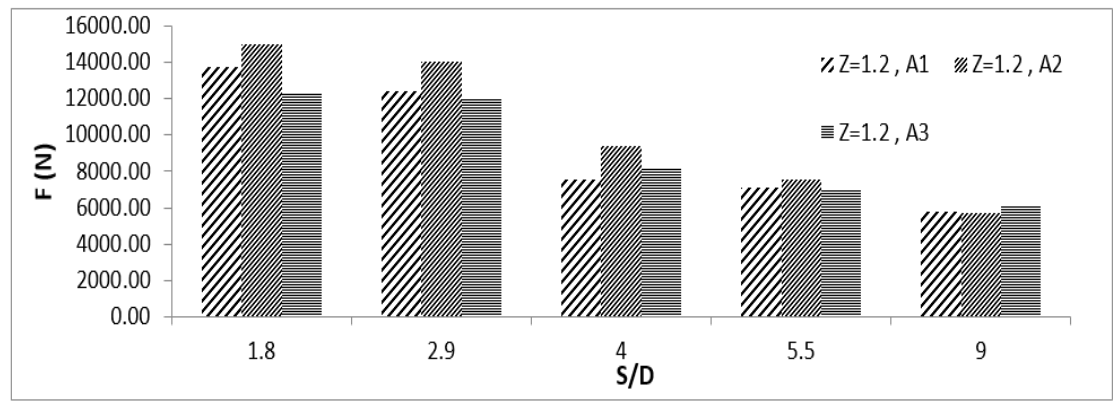

Figure 4. The average force applied to the row A with diameter ratio of $\mathrm{Z}=1.2$ and different distances 


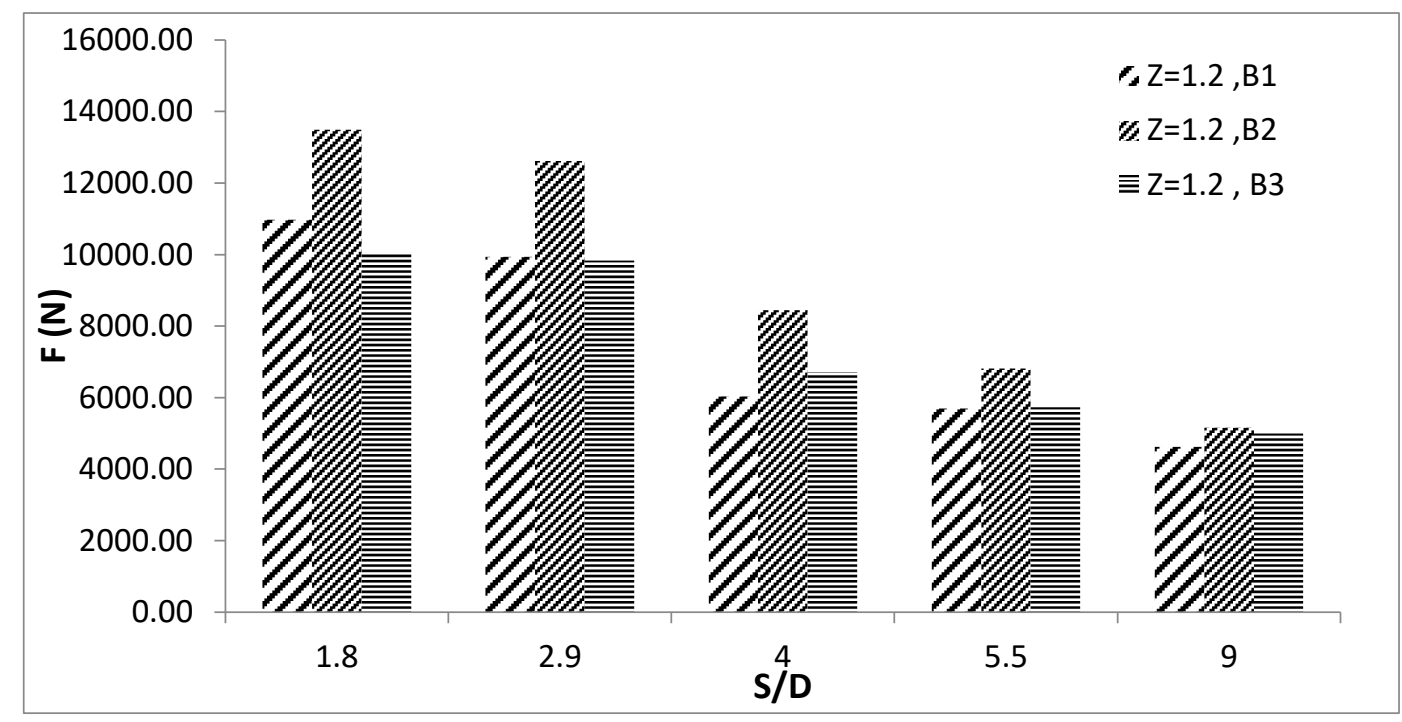

Figure 5. The average force applied to the row $\mathrm{B}$ with diameter ratio of $\mathrm{Z}=1.2$ and different distances

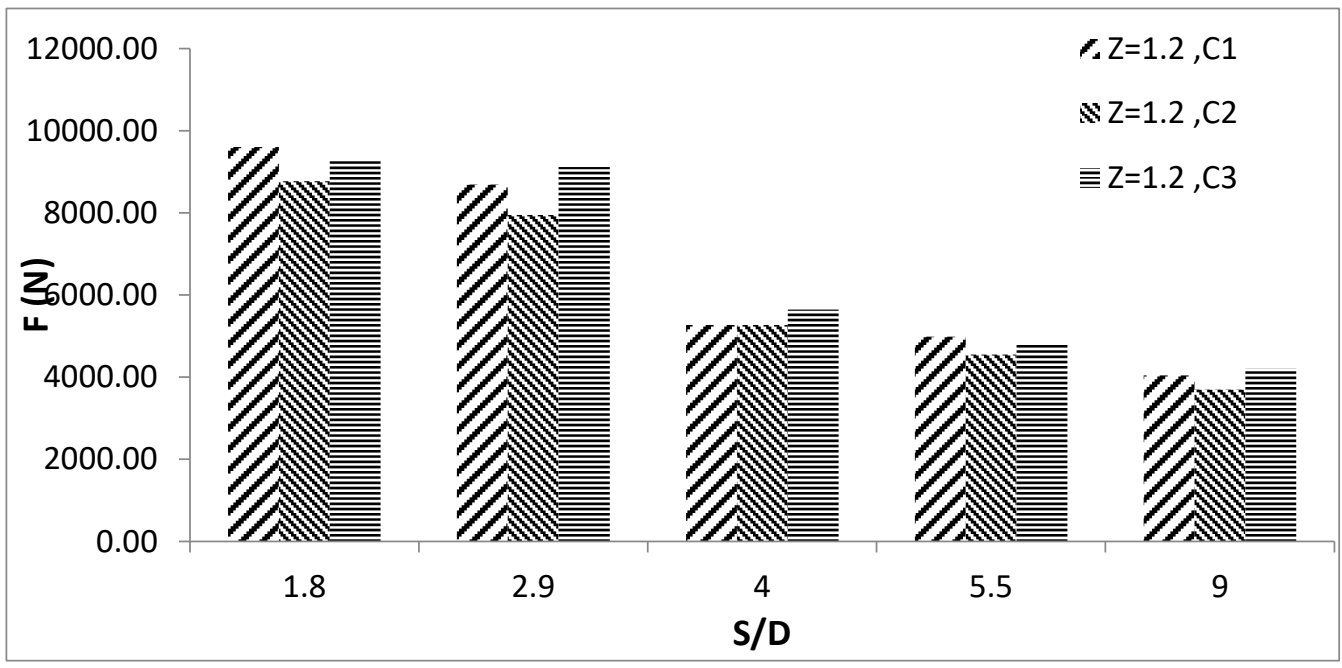

Figure 6. The average force applied to the row $\mathrm{C}$ with diameter ratio of $\mathrm{Z}=1.2$ and different distances

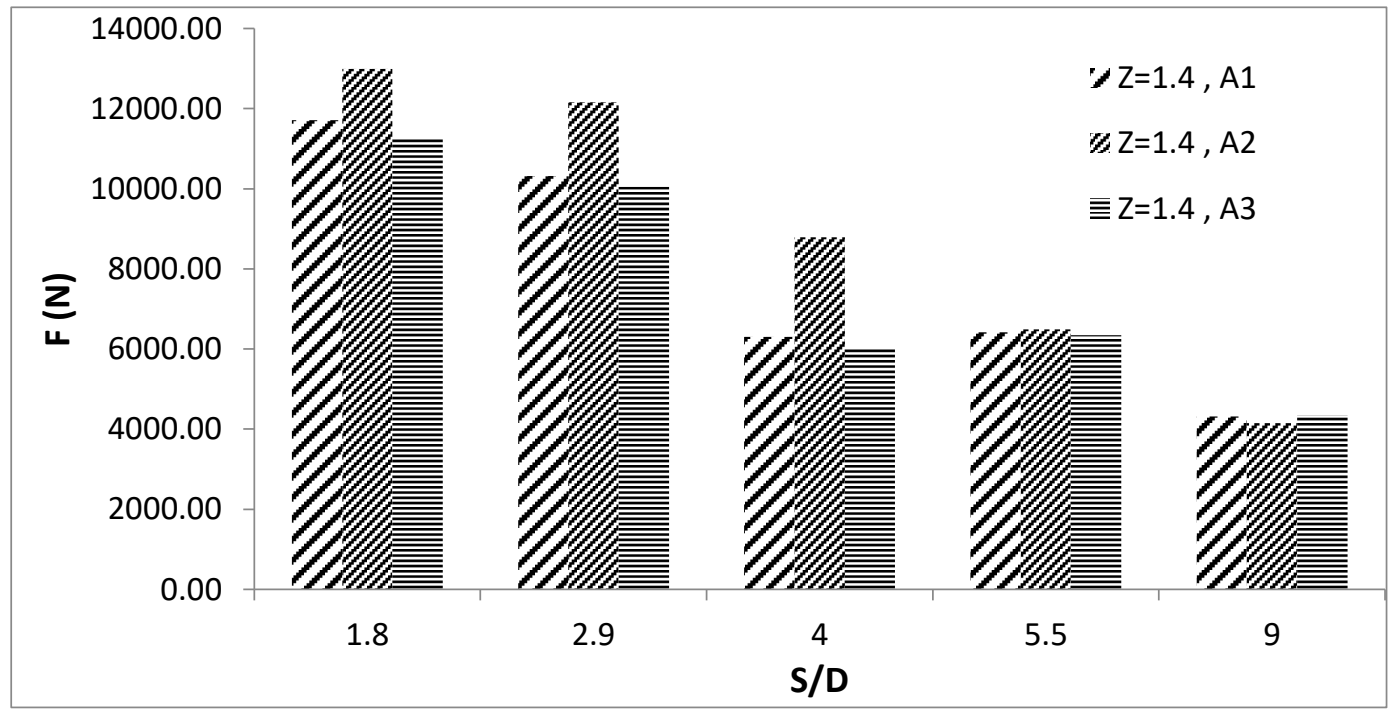

Figure 7. The average force applied to the row $A$ with diameter ratio of $Z=1.4$ and different distances 


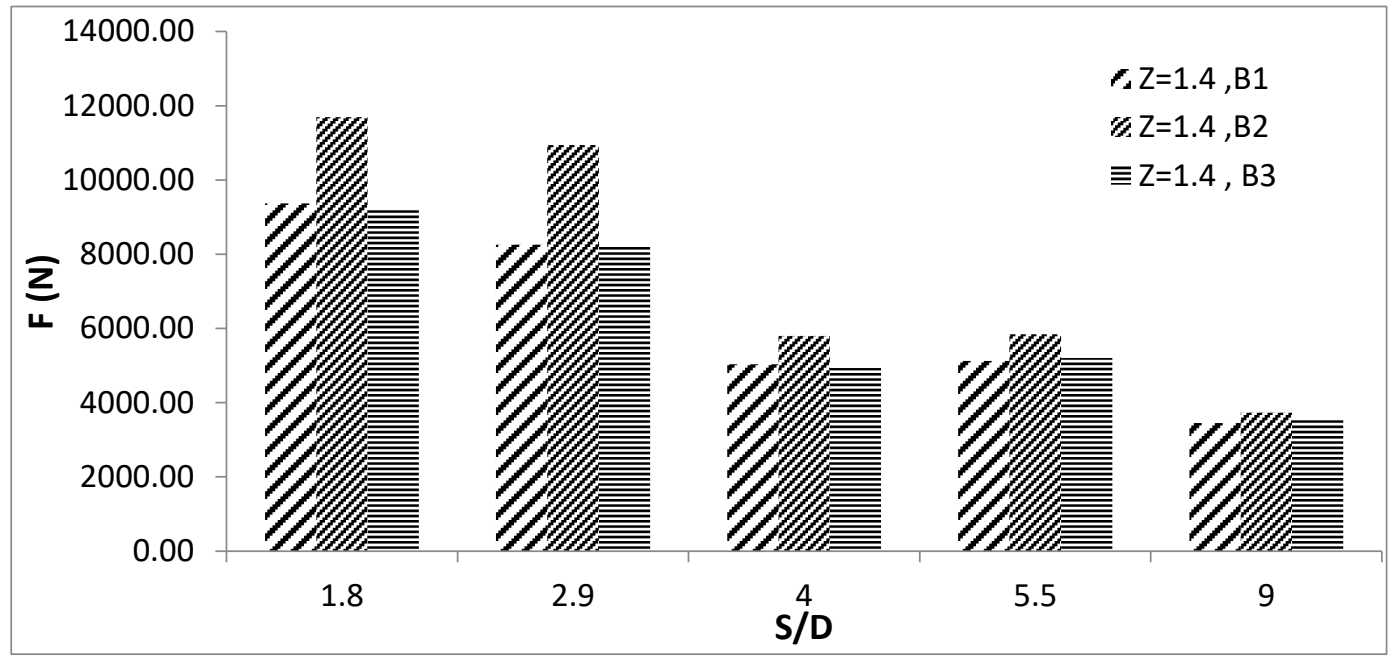

Figure 8. The average force applied to the row $\mathrm{B}$ with diameter ratio of $\mathrm{Z}=1.4$ and different distances

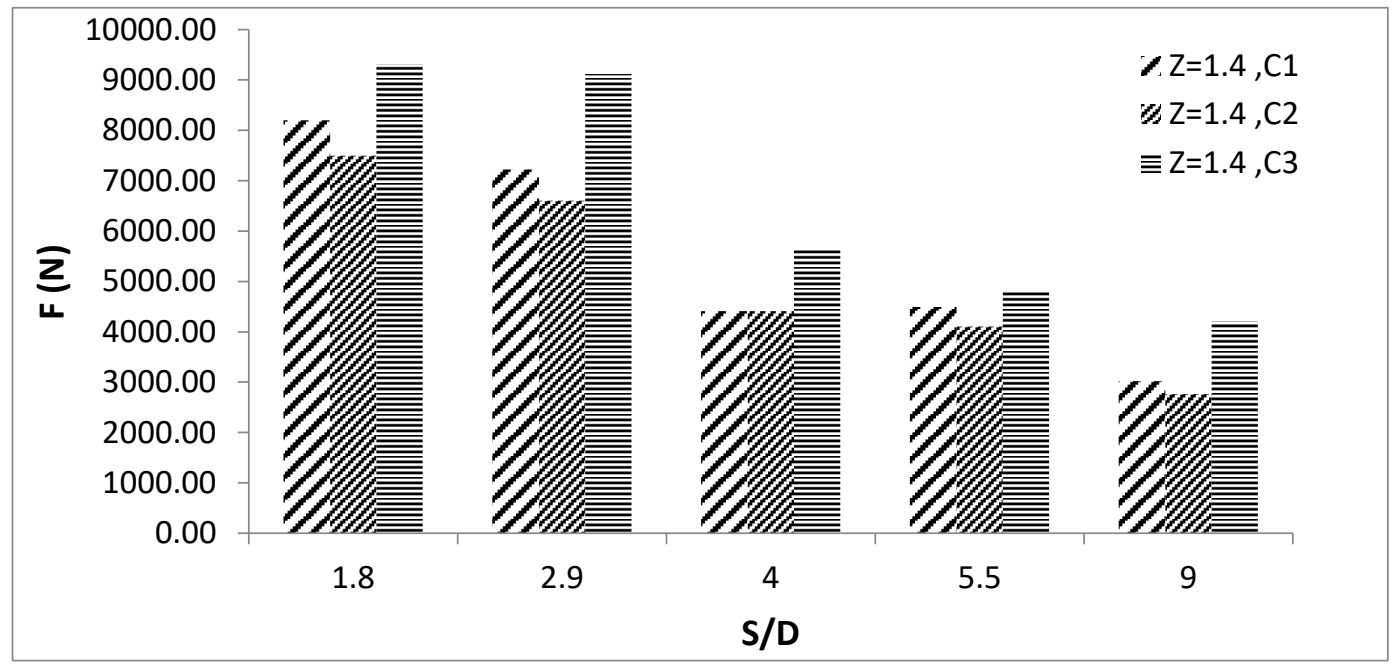

Figure 9. The average force applied to the row $\mathrm{C}$ with diameter ratio of $\mathrm{Z}=1.4$ and different distances

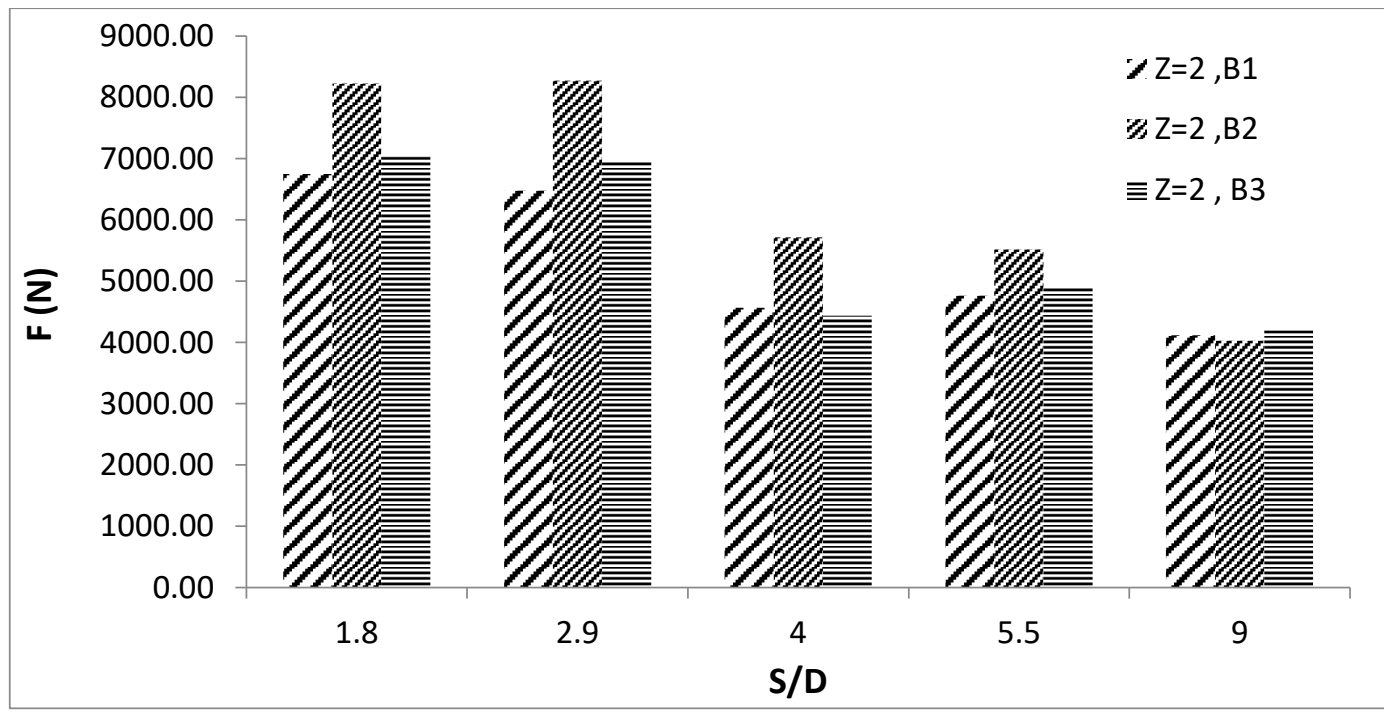

Figure 10. The average force applied to the row A with diameter ratio of $\mathrm{Z}=2$ and different distances 


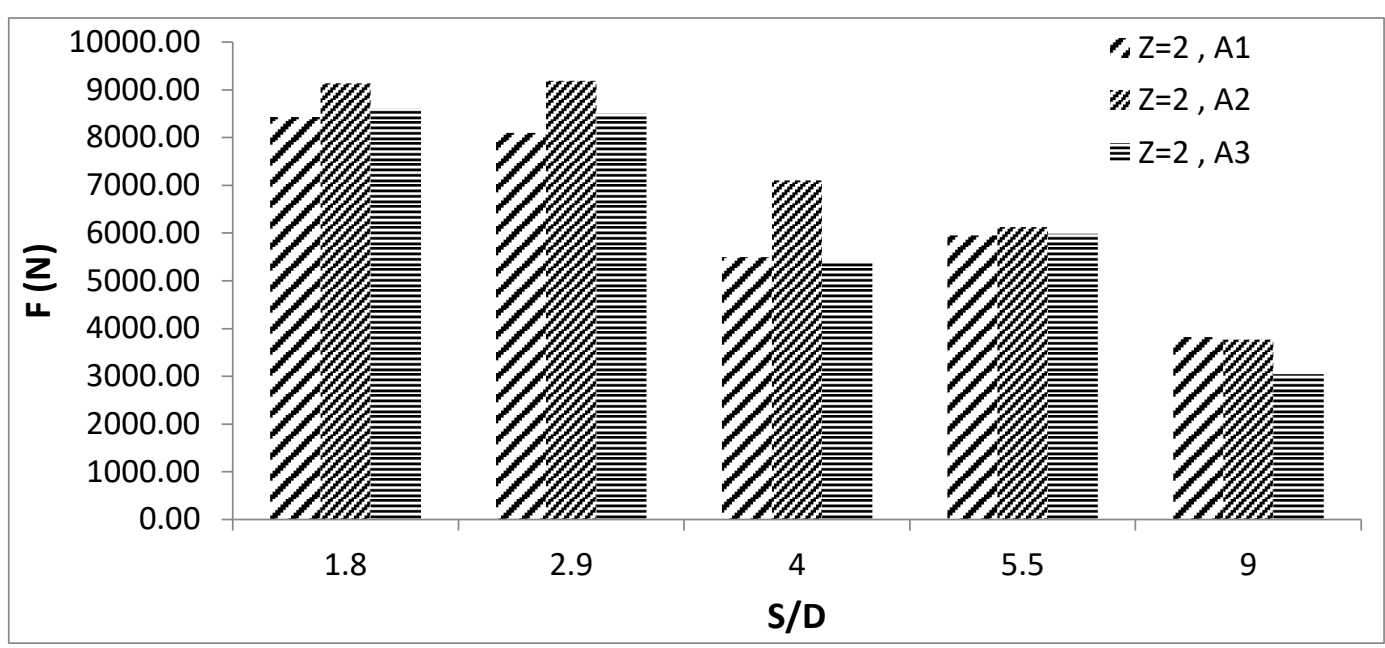

Figure 11. The average force applied to the row $\mathrm{B}$ with diameter ratio of $\mathrm{Z}=2$ and different distances

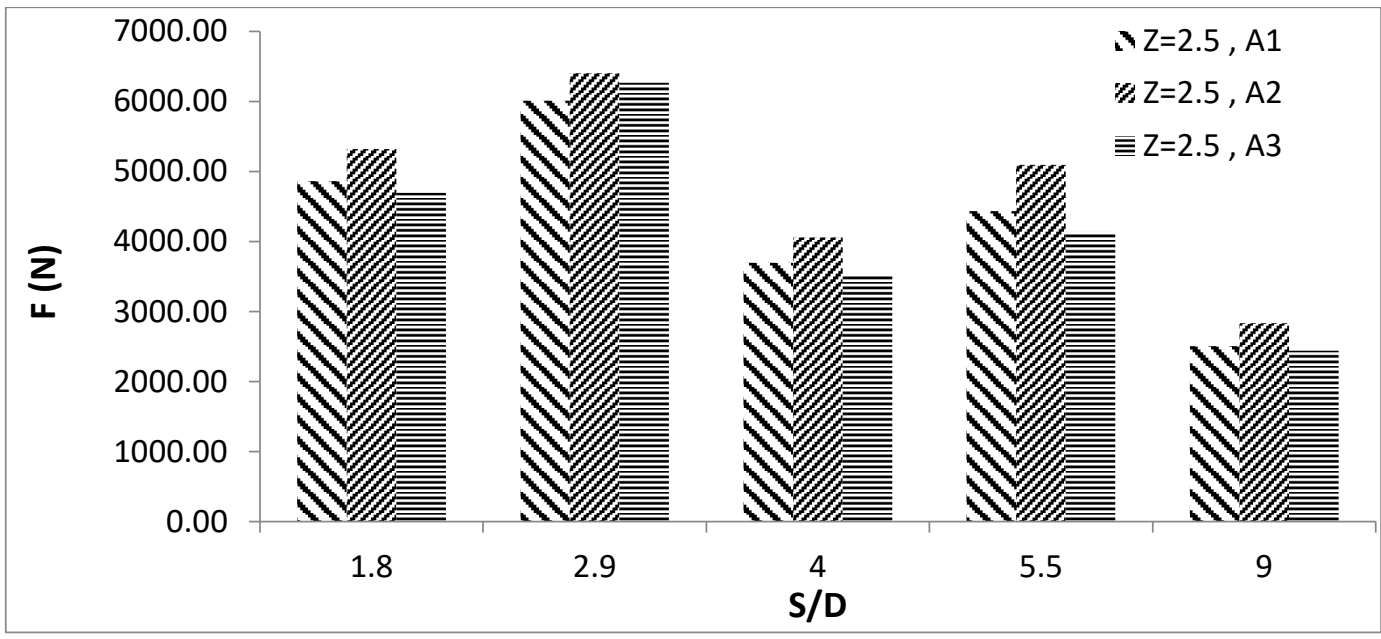

Figure 12. The average force applied to the row $\mathrm{C}$ with diameter ratio of $\mathrm{Z}=2$ and different distances

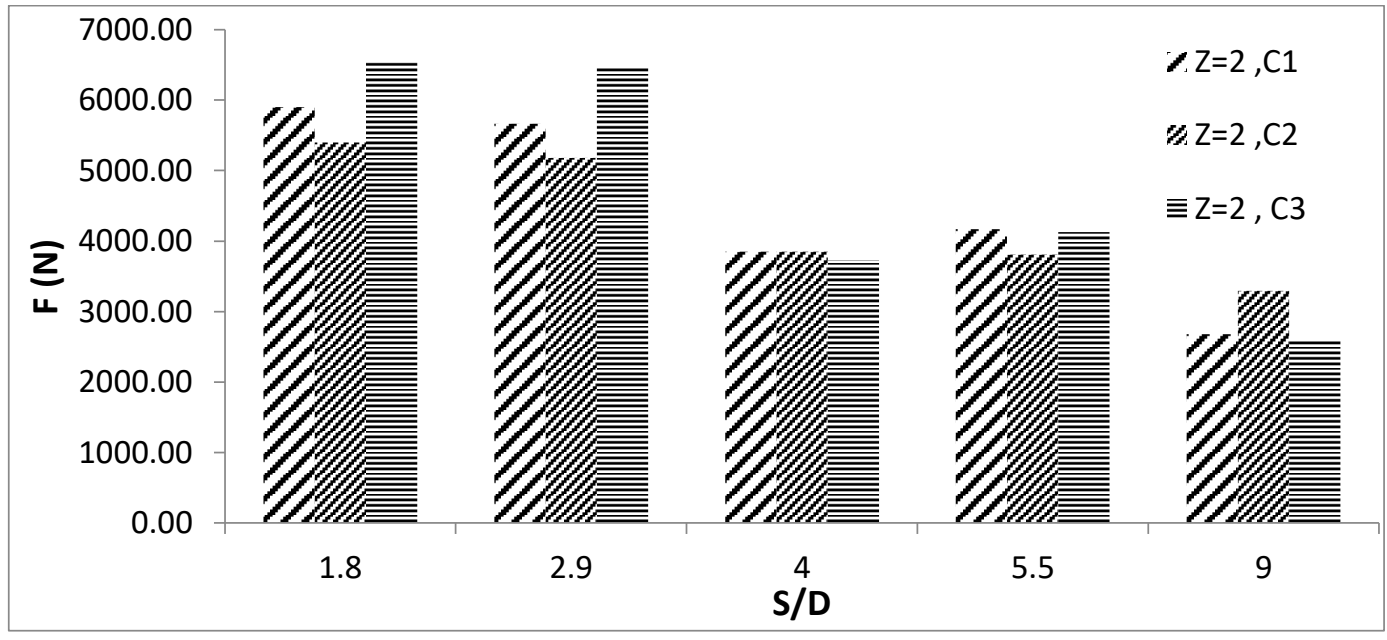

Figure 13. The average force applied to the row $\mathrm{A}$ with diameter ratio of $\mathrm{Z}=2.5$ and different distances 


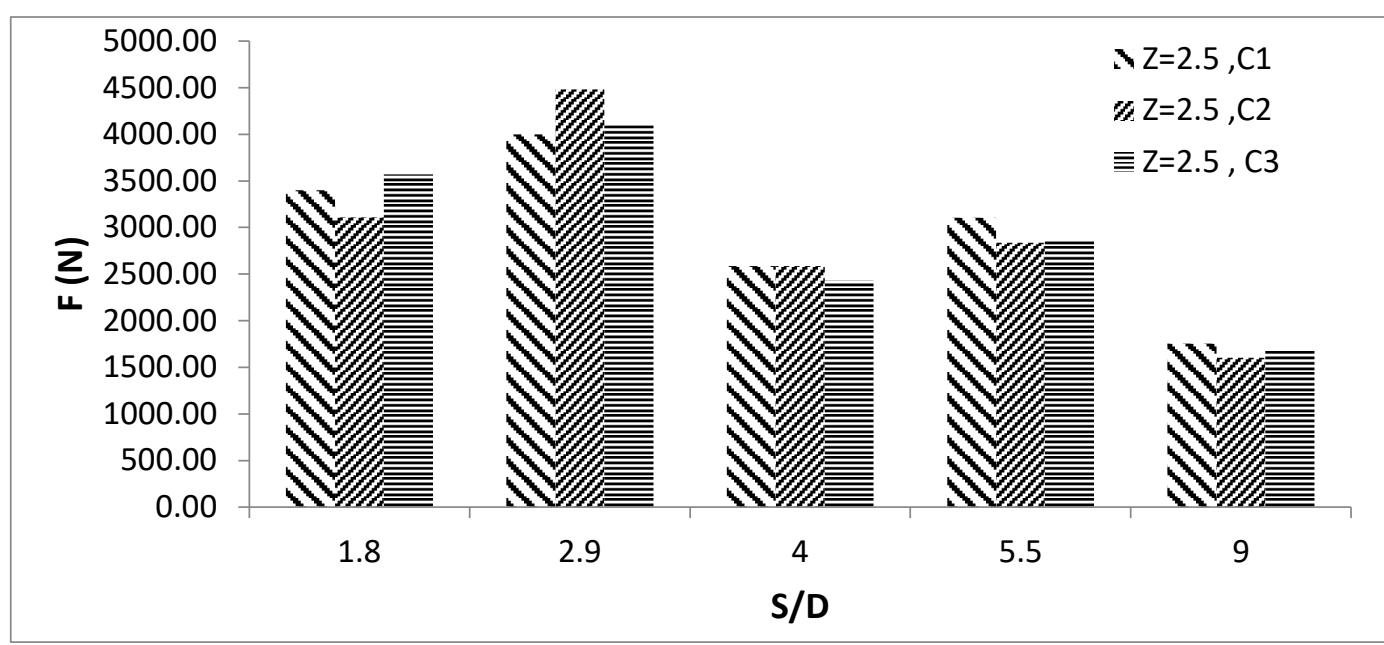

Figure 14. The average force applied to the row $\mathrm{B}$ with diameter ratio of $\mathrm{Z}=2.5$ and different distances

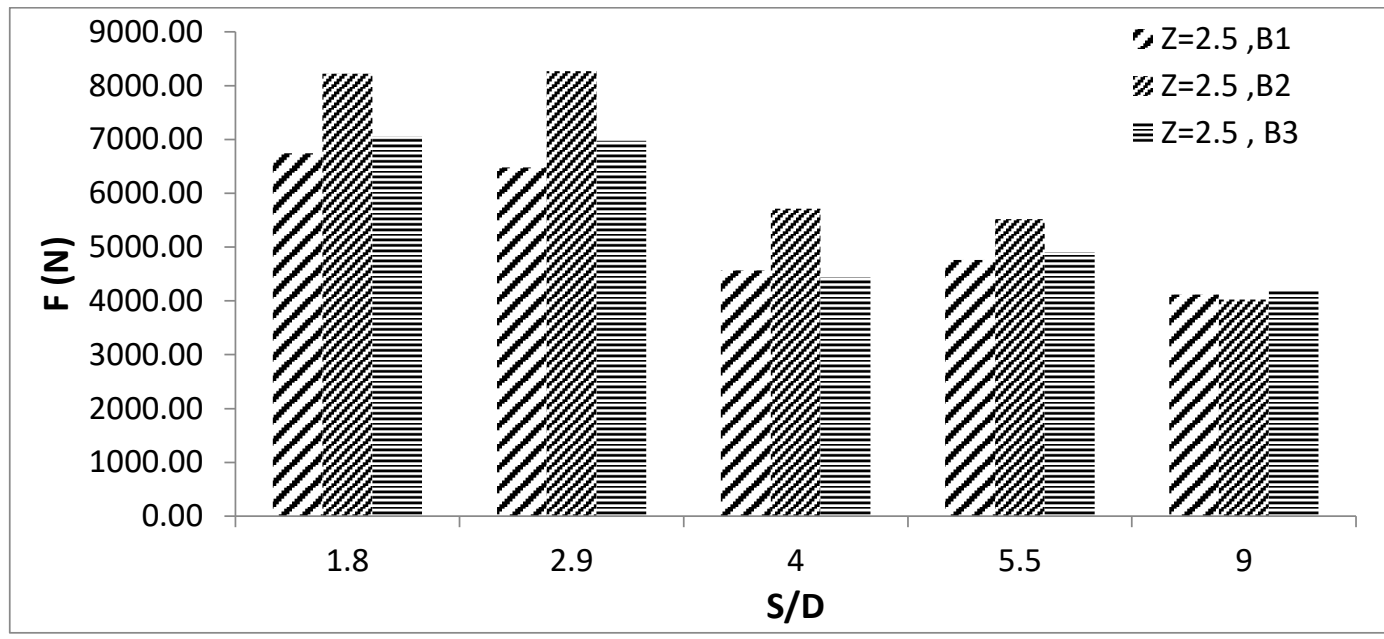

Figure 15. The average force applied to the row $\mathrm{C}$ with diameter ratio of $\mathrm{Z}=2.5$ and different distances

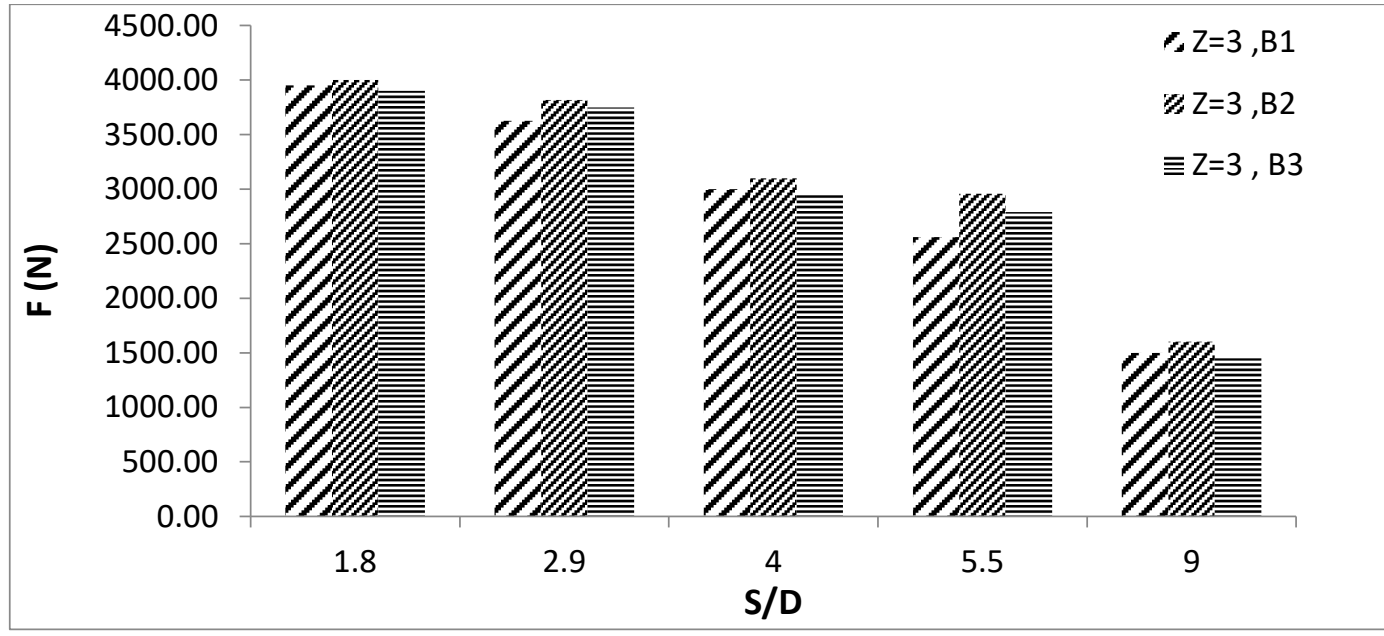

Figure 16. The average force applied to the row $A$ with diameter ratio of $Z=3$ and different distances 


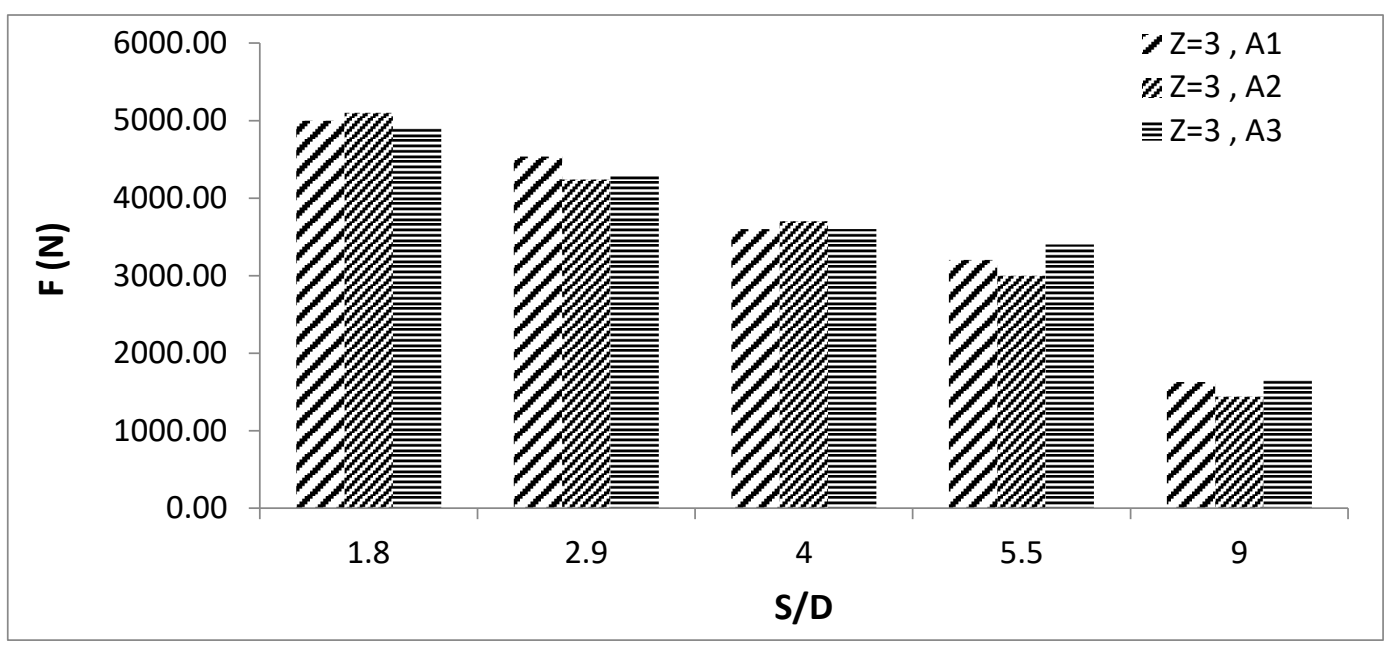

Figure 17. The average force applied to the row $\mathrm{B}$ with diameter ratio of $\mathrm{Z}=3$ and different distances

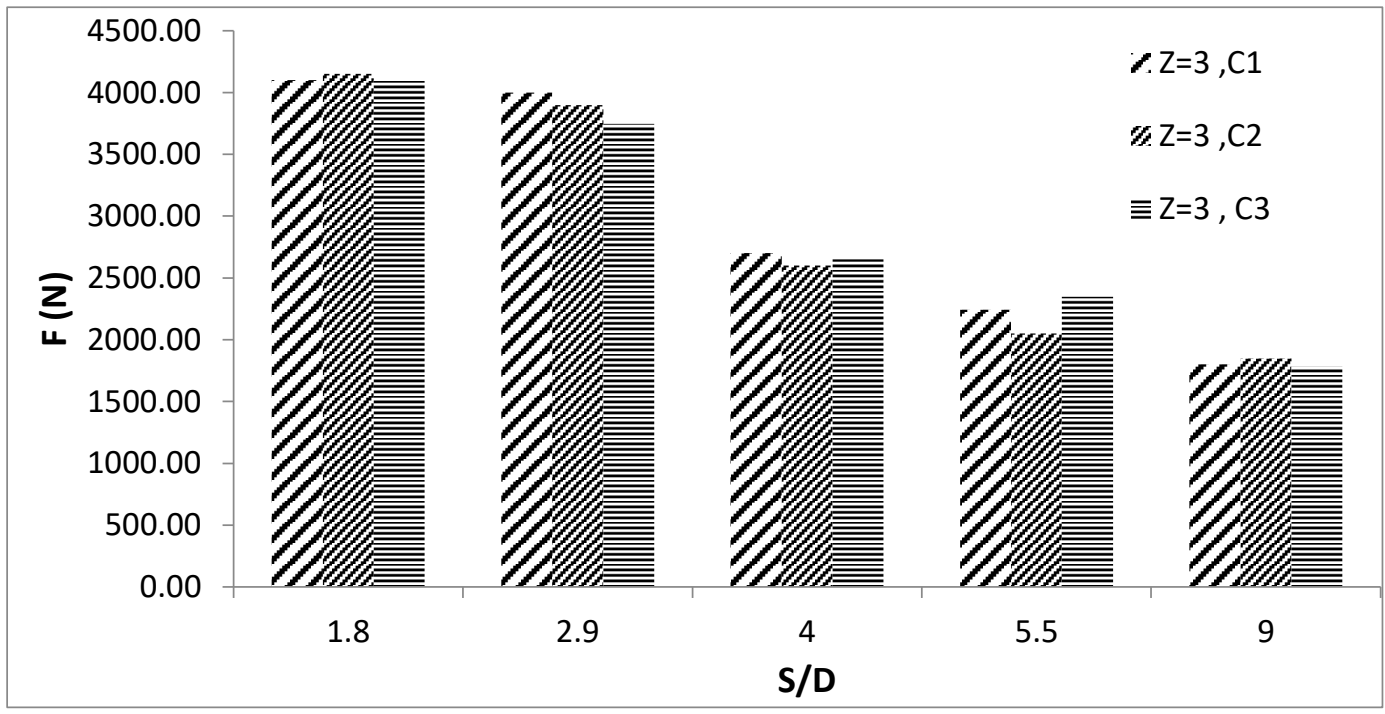

Figure 18. The average force applied to the row $\mathrm{C}$ with diameter ratio of $\mathrm{Z}=3$ and different distances

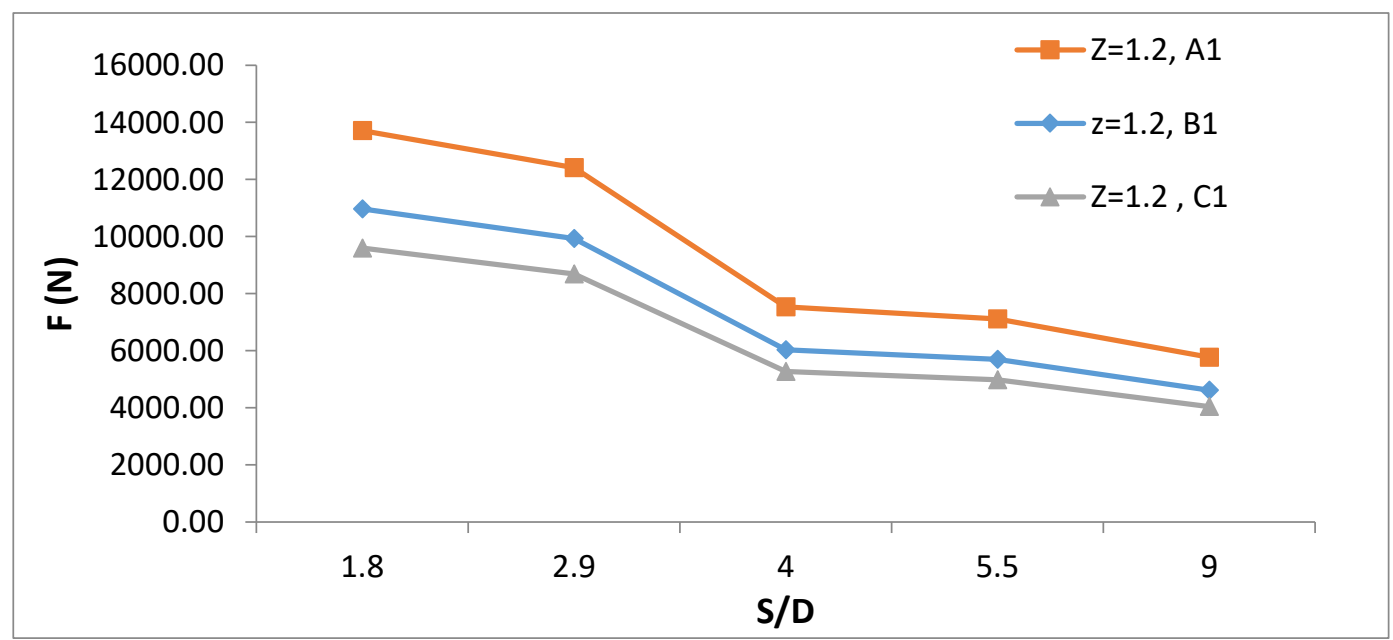

Figure 19. The average force applied to the row 1 with diameter ratio of $Z=1.2$ and different distances 


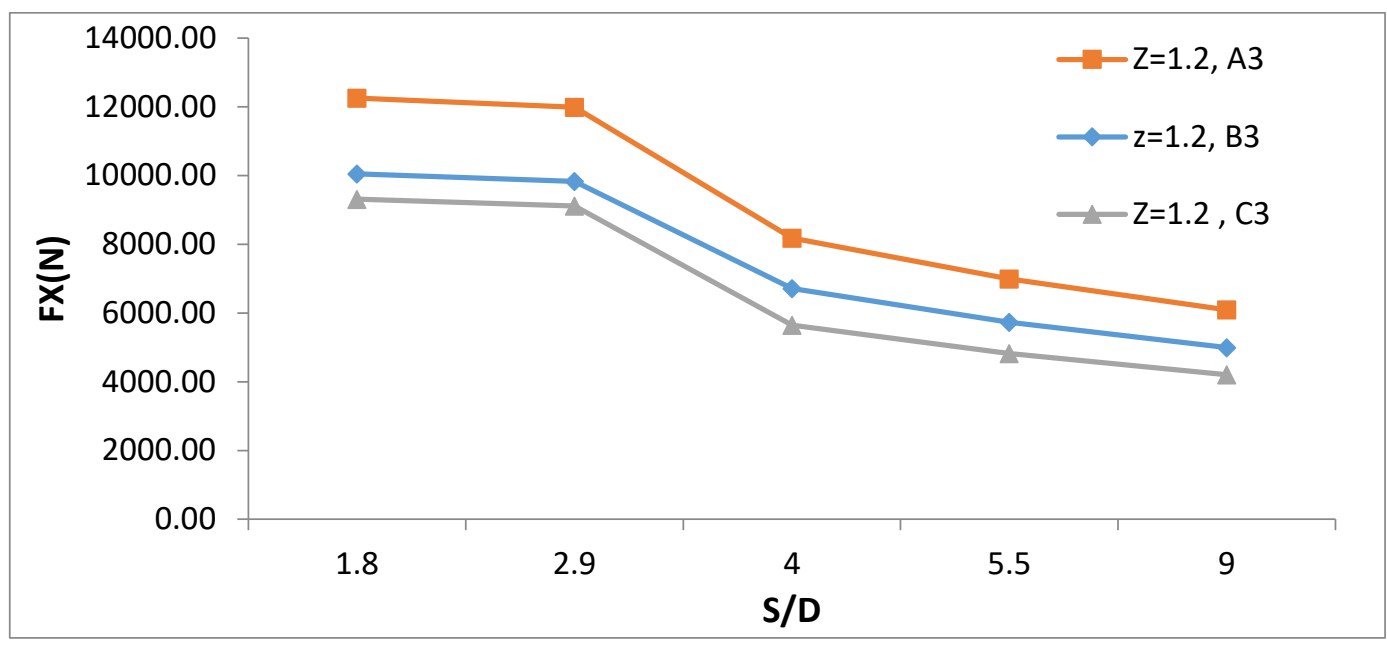

Figure 20. The average force applied to the row 2 with diameter ratio of $Z=1.2$ and different distances

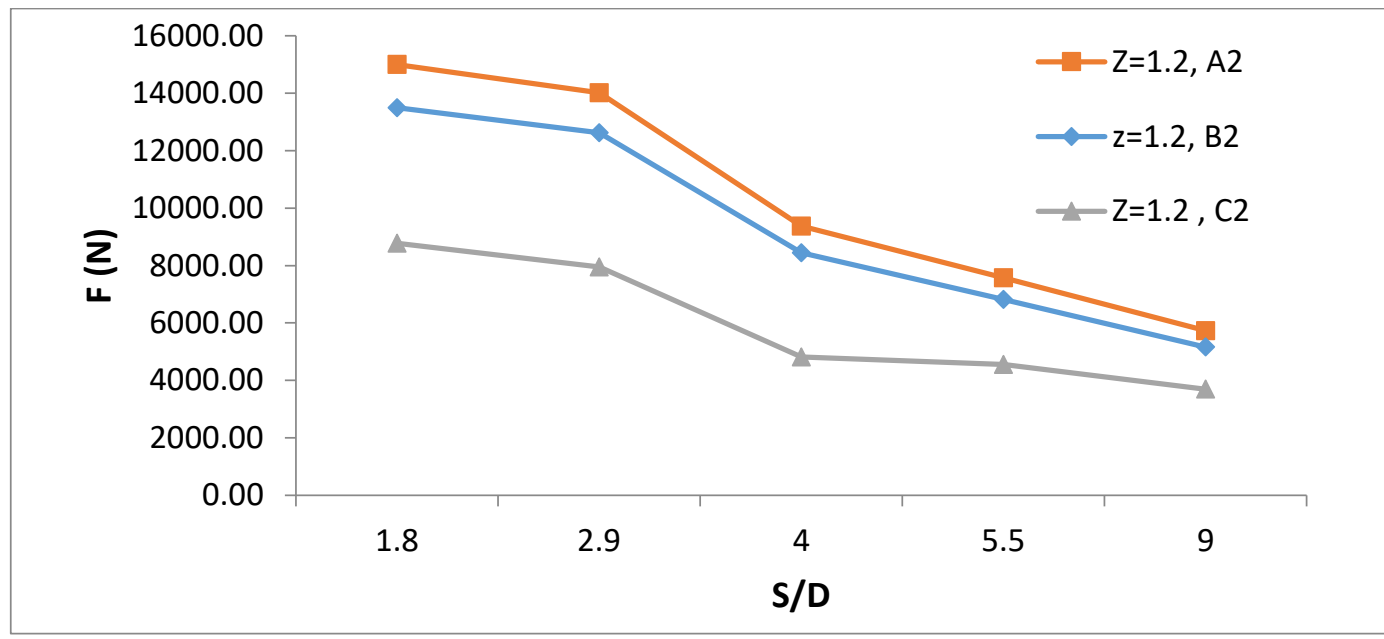

Figure 21. The average force applied to the row 3 with diameter ratio of $\mathrm{Z}=1.2$ and different distances

\section{REFERENCES}

Ghatarband, M. and M. BehdarvandiAskar; 2016. Investigation of the Effect of the Circular Stands Diameters of Marine Structures and the Distances between Them on Wave Run-up and Force." Marine Science 6(1): 11-15.

Yanfei Deng, J,Yang, L, X and YugaoShen; 2014. Frequency analysis of wave run-up on vertical cylinder in transitional water depth" Ocean Systems Engineering, Vol. 4, No. 3 (2014) 201-213.

J.X., Wang, Z. and Shu-xue, L; 2012. Experimental Study of interactions between multi-directional focused waves and vertical circular cylinder, Part I: Wave run-up, Coast. Eng., 64, 151-160.

Isaacson, M.; 1978. Wave runup around large circular cylinder.WtrwaysPort, Coast, and Oc. Div., ASCE, 104(1), 6979 .
Hallermeier, R. J., 1976. Nonlinear flow of wave crests past a thin pile. JWtrways., Harbors and Coast. Engrg. Div., ASCE, 102(4), 365-377.

Galvin, C. J., and Hallermeier, R. J.; 1972. Wave run-up on vertical cylinders Proc. 13th Int. Conf. on Coast. Engrg., ASCE, 1955-1974.

Haney, J. P., and Herbich, J. B.; 1982. Wave flow around thin piles and pilegroups. Hydr. Res., 20(1), 1-14.

Rashidinasab, M. and M. BehdarvandiAskar; 2017. Modeling the Pressure Distribution and the Changes of Water Level around the Offshore Platforms Exposed to Waves, Using the Numerical Model of Flow 3D. Computational Water, Energy, and Environmental Engineering 06(01): 97-106.

Bahadori, S. and M. BehdarvandiAskar; 2016. Investigating the Effect of Relative Depth and Relative Roughness on Momentum Transfer in Symmetric Rectangular Compound Channels with Varius Relative Width. International Journal of Hydraulic Engineering 5(1): 1-8. 
Ebrahimi, A., et al.; 2015. Investigation of Various Random Wave Run-up Amounts under the Influence of Different Slopes and Roughnesses. Environment Conservation Journal 16(Special Issue): 301-308.

Deilami-Tarifi, M., et al.; 2016. Modeling of the Changes in Flow Velocity on Seawalls under Different Conditions Using FLOW-3D Software." Open Journal of Marine Science 6: 317322. 